\title{
O ENSINO DA REPRESENTAÇÃO GRÁFICA NOS CURSOS DE DESIGN: MAPAS MENTAIS E CONCEITUAIS, FERRAMENTAS DE ESTRUTURAÇÃO DE CONTEÚDOS
}

Eliete Auxiliadora Assunção Ourives, Drª Universidade Federal de Santa Catarina elieteourives@gmail.com

Alais Souza Ferreira

Especialização em Marketing Criativo UNIVALI

alais.ferreira@live.com
Luiz Fernando Gonçalves de Figueiredo, Dr. Universidade Federal de Santa Catarina Iffigueiredo2009@gmail.com

Milton Luiz Horn Vieira, Dr. Universidade Federal de Santa Catarina milton@cce.ufsc.br

Ludmilla Gonçalves de Figueiredo Graduada em Serviço Social - UFSC ludy.figueiredo@gmail.com

Resumo: A representação gráfica é utilizada nos projetos gráficos dos cursos de design para a concepção, comunicação e documentação de ideias, permitindo o estudo do conceito de espaço e seus atributos - tais como formas, dimensão e posição relativa -, além de ajudar o estudante a desenvolver seu potencial criativo, habilidade de visão espacial e o raciocínio lógico. Os mapas mentais e conceituais são ferramentas eficientes para proporcionar o ensino e aprendizagem, do conteúdo da representação gráfica, pois instigam uma nova percepção na maneira de ensinar e aprender criando um ambiente propício a compreensão e interpretação de informações, conceitos e ideias. Eles também ajudam o estudante a integrar e relacionar conhecimentos, atribuindo significado ao que está sendo estudado. Visando essa finalidade, o objetivo deste trabalho foi utilizar os mapas mentais e conceituais como ferramentas de estruturação de conteúdo da representação gráfica nos cursos de design. 0 método de pesquisa deste artigo tem caráter descritivo e exploratório. Ao final, este estudo vem contribuir indicando o uso dos mapas mentais e conceituais como recurso de aprendizagem, por estimular a curiosidade, motivação, aprendizado e desenvolver o senso cognitivo dos alunos, assim como oferecer estratégias que o professor pode ter disponível como meio para o ensino.

Palavras-chave: design, representação gráfica, mapas mentais e conceituais.

Abstract: The graphical representation is used in graphic projects of the design courses for conception, communication and documentation of ideas, allowing the study of the concept of space and its attributes - such as shape, dimension, and relative position -, In addition to helping the student to develop their creative potential, ability of spatial vision and logical reasoning. The mental and conceptual maps are tools efficient to provide 
teaching and learning, of the contents of graphic representation, because instigate a new perception in way of teaching and learning by creating an enabling environment to understanding and interpretation of information, concepts and ideas. They also report the student to integrate and relate knowledge, assigning meaning to what is being studied. Aiming to this purpose, the aim of this study was to use the mental and conceptual maps as tools for structuring content of graphic representation in design courses. The method of research of this article has descriptive and exploratory character. In the end, this study comes to contribute indicating the use of the mental and conceptual maps as learning resource, to stimulate curiosity, motivation, learning and develop cognitive sense of students, as well as offer strategies that the teacher may have available as a means for teaching.

keywords: design, graphic representantion, mental and conceptual maps.

\section{INTRODUÇÃO}

$\mathrm{O}$ ensino baseado em projetos, também chamado de projeto didático ou projeto de trabalho, esquematizado pelo professor, é uma proposta de organização e desenvolvimento do conteúdo acadêmico que envolve a participação dos alunos. 0 papel do professor é propor problemas e orientar os alunos na busca da solução, já o do aluno é participar da construção do conhecimento por meio da pesquisa.

$\mathrm{Na}$ atividade docente, o professor: busca material para a realização do projeto; estuda para preparar o tema e orientar os alunos; desenvolve formas de envolver os componentes do grupo; mostra a importância do tema para o grupo, com vistas ao mundo atual; mantém postura de avaliação processual e formativa; e desenvolve atitude de planejamento, partindo do que foi feito para o que deve ser realizado.

Ao abordar o tema, o professor deve considerar e propiciar o desenvolvimento de vários aspectos relevantes ao ensino: despertar o interesse pelo conhecimento científico; contribuir para o desenvolvimento de habilidades cognitivas (observar, comparar, classificar, formular e testar hipóteses, experimentar, estabelecer relação de causa e efeito, entre outras); designar relação com outras áreas de conhecimento, contemplando a interdisciplinaridade e transversalidade.

Este trabalho articula o conteúdo e a didática para o ensino, envolvendo: a prática; o uso de diferentes atividades em sala de aula e o significado das mesmas na aprendizagem; o planejamento e análise de ações no processo de seleção e/ou produção de material sobre as concepções da representação gráfica, implícitas ou explícitas para o curso de design entre outros com áreas afins. Portanto, o conceito de produção não significa fazer algo totalmente novo, mas realizar a seleção e a adequação de materiais aos objetivos do ensino. É importante destacar que o conteúdo da representação gráfica acumulou um significativo acervo de propostas para o trabalho de sala de aula, que é o ponto de partida para aprimorar a formação dos alunos. Conhecer tais propostas, saber avaliá-las, selecionar e adequar as que podem contribuir para a aprendizagem é parte fundamental da formação docente. 
A estratégia abordada neste estudo propõe a utilização de mapas mentais e conceituais para a estruturação do conteúdo da representação gráfica, especificamente sobre o processo analógico, pois mesmo com o uso de programas CAD (Computer Aided Design), etc, o esboço, os croquis, o desenho e as maquetes reais ainda continuam sendo instrumentos que contribuem no processo de ensino e aprendizagem. Conforme Gargioni de Souza (2004) a construção desses mapas desenvolve no aluno a habilidade de organização das informações, possibilitando que o processo de armazenamento delas seja incorporado à memória de longo prazo (estrutura do cérebro) para que ele possa manipular estas informações e utilizá-las em seus trabalhos futuros.

Ao desenvolver o tema, os mapas mental e conceitual admitem trabalhar com diferentes habilidades cognitivas e envolver os alunos na busca de informações. Assim, eles conseguem perceber a importância dos vários elementos no processo de construção da informação referentes à representação gráfica e como o conhecimento dos mesmos ajuda na construção de objetos gráficos, desde os mais simples até aos mais complexos, permitindo interceptar-los, seccioná-los, planificá-los e modelá-los.

Para que isso ocorra, a estrutura de conhecimento proposta pelos professores precisa desafiar e estimular o sistema cognitivo, atingindo estágios elevados de raciocínio na formação do conceito e potencializando o desenvolvimento da habilidade viso espacial do aluno. Isso é possível ao utilizar como ferramenta os mapas mentais e conceituais, conforme Vygotsky (1998) o meio tem que: desafiar, exigir e estimular o intelecto, senão este estágio pode atrasar ou não se completar, não atingindo estágios mais elevados de raciocínio na formação do conceito. Então, este trabalho objetiva sistematizar os métodos de representação gráfica utilizando esses mapas como ferramentas de estruturação de conteúdos nos cursos de design.

\section{ENSINO E APRENDIZAGEM UTILIZANDO MAPAS MENTAIS E CONCEITUAIS}

Para Hermann (2015), quando a pessoa é submetida a algo novo ela compara com o que já conhece, o que seria uma abordagem estrutural para depois registrar a nova informação, que seria a memorização do conteúdo ou simplificar o conteúdo encaixando em outro já existente, que seria uma abordagem redutora. $\mathrm{O}$ autor adverte que se o conteúdo novo não satisfizer um padrão conhecido após a abordagem estrutural ou redutora, esse conteúdo será abandonado ou esquecido. Moretto (2003) afirma que é necessário aproveitar a estrutura cognitiva do aluno - conhecimentos anteriores -, formadas pelo conjunto de suas ideias, experiências e paradigmas ligados ao senso comum para propor as concepções acadêmicas. Para facilitar esse aprendizado cognitivo, o professor precisa resgatar esses conhecimentos anteriores para apresentar o novo de maneira que se adapte a concepção de mundo do aluno.

Dentre as variadas técnicas de ensino e aprendizagem, este projeto optou pela abordagem dos mapas mentais e conceituais devido à simplicidade dos mesmos e a facilidade que proporcionam na aprendizagem de conteúdos. Além disso, eles favorecem a transmissão de conhecimentos práticos com vista à memorização de procedimentos, pois se torna mais fácil interiorizar uma sequência de procedimentos práticos através da análise de um esquema misto texto/imagem. A seguir será apresentado o conceito, definição e uso no ensino de ambos os mapas. 


\subsection{Mapa Mental}

É um tipo de diagrama, sistematizado pelo inglês Tony Buzan, voltado para: gestão de informações e conhecimentos; compreensão e solução de problemas; memorização e aprendizado; criação de manuais, livros e palestras; como ferramenta de brainstorming; e no auxílio da gestão estratégica de empresas, negócios, etc. Pode ser aplicado a qualquer tarefa ou atividade profissional, individualmente ou em grupo. Tony Buzan observou que os alunos que faziam uso de estratégias de trabalho e de anotações diferenciadas, com cores, desenhos, símbolos e ilustrações obtinham melhores resultados de aprendizagem que os alunos que não usavam tais métodos, ou seja, a exploração dos hemisférios direito e esquerdo do cérebro no processo de aprendizagem proporcionava melhor absorção do conhecimento (HERMANN, 2005).

A utilização desse mapa fornece uma nova conotação na aprendizagem, passando da aquisição isolada de informações para as relações entre elas, ganhando significado cognitivo e lançando o conceito de aprendizagem significativa (MORETTO, 2003). O aluno pode fazer as anotações em aula e elaborar o mapa em casa. Com o tempo, ele vai ganhando agilidade e consegue anotar o conteúdo da aula em mapa mental - que é uma técnica que auxilia o processo de organização e hierarquização do pensamento, melhorando compreensão das informações sobre o conteúdo.

O sistema de diagrama dos mapas mentais funciona como uma representação gráfica das ideias que se organizam em torno de um foco. Os desenhos feitos nesses mapas partem de um único centro, do qual são irradiadas as informações relacionadas. Ao montá-lo, você vai raciocinando em cima do conteúdo e vai quebrando essas informações em partes, onde cada parte é associada com o restante, criando conexões entre cada conceito. A construção dele consiste no encadeamento hierarquizado das informações de maneira não linear com ilustrações que auxiliem na memorização e aprendizado dos conteúdos abordados (BUZAN, 1996).

A figura 1 apresenta o uso do mapa na disciplina de química, com o tema Hidrocarbonetos. Observa-se que o aluno criou cinco ramificações, pois esses compostos possuem classificações específicas e cada uma delas tem nomenclatura própria. Segundo os alunos, o esquema facilitou o entendimento e memorização do conteúdo para a prova.

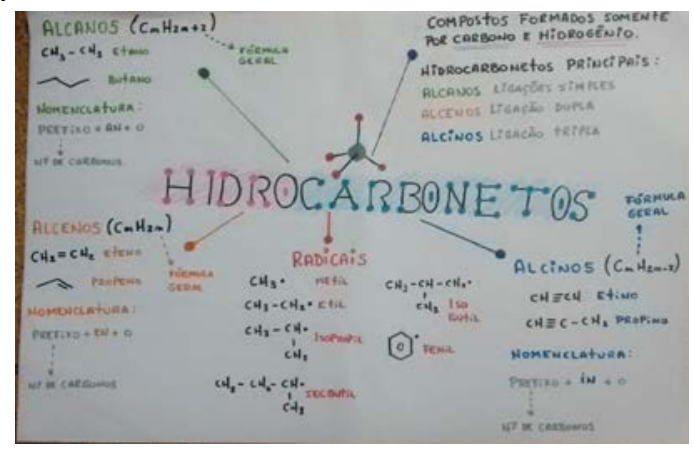

Figura 1 - Mapa mental de Química (Hidrocarbonetos).

Fonte: http://desconversa.com.br/quimica/mapa-mental-hidrocarbonetos/

Gargioni de Souza (2004) utilizou mapas mentais no ensino para realizar um redesign da representação gráfica espacial. Segundo a autora, através dos mesmos é possível trabalhar as informações em nível contextual, organizacional e metodológico a respeito do desenvolvimento de habilidades representativas gráficas, construtivas e 
visuais em relação à técnica do Sistema Mongeano. A autora informa que a finalidade dessa estrutura é melhorar e facilitar o processo de organização, através do registro e recuperação das informações - no sentido de desenvolver a habilidade viso-espacial do aluno, professor, pesquisador e outros interessados. Isso ocorre pela estrutura de raciocínio que tem como base "os procedimentos da memória humana, através do emprego da teoria da rotação mental e do processo de relembrar associado a construção de mapas mentais" (GARGIONI DE SOUZA, 2004 p.1). A figura 2 mostra o mapa do método proposto pela autora.

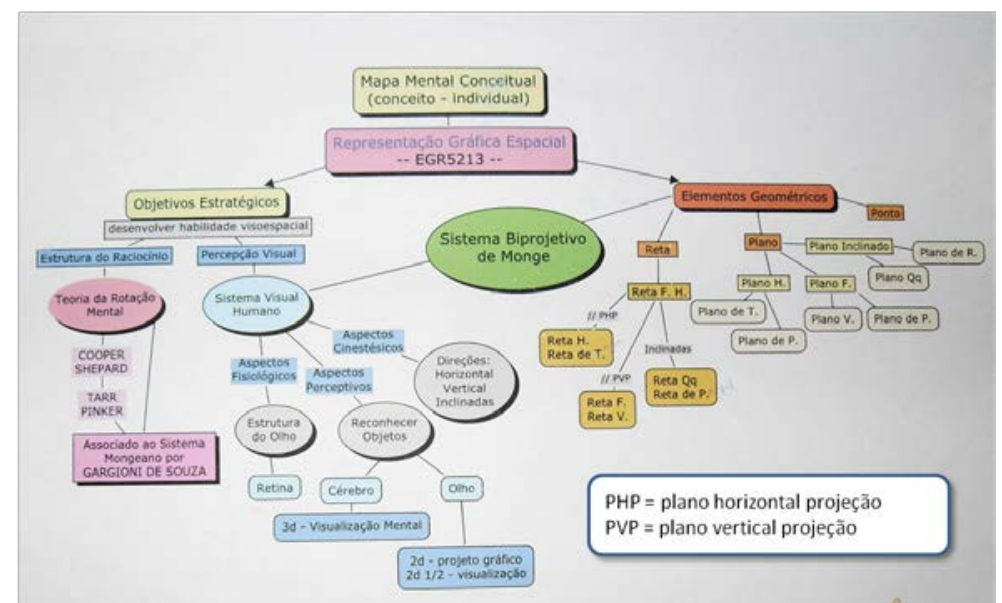

Figura 2 - Mapa mental da representação espacial segundo o Sistema Bi projetivo de Monge. Fonte: Gargioni de Souza (2004).

Com base na teoria apresentada sobre os mapas mentais, esta pesquisa pretende trabalhar de forma conjunta com os mapas conceituais, que serão apresentados a seguir, a fim de contribuir para o entendimento da representação gráfica, auxiliando os alunos na construção dos seus projetos gráficos.

\subsection{Mapa conceitual}

O pesquisador norte-americano Joseph Novak, é considerado o criador da teoria dos mapas conceituais, que foi baseado na teoria da aprendizagem significativa construtivista de David Ausubel (Novak, 1977). Segundo Bax \& Souza (2008), nesta teoria o indivíduo constrói o seu conhecimento e significado, que facilita o aprendizado do conteúdo sistematizado em conteúdo significativo. Esses mapas podem ser aplicados de modo individual ou em grupo para qualquer tipo de assunto.

A estratégia de Novak (1977), criada a partir dos princípios da teoria de Ausubel (1968), organizou os mapas para serem utilizados no processo de ensino e se baseia na: diferenciação progressiva (relação entre proposições e conceitos, semelhanças e diferenças), onde as ideias mais gerais e inclusivas são apresentadas no início do mapa para depois serem diferenciadas; e reconciliação integrativa (cada nova informação permite o deslocamento das hierarquias conceituais evidenciando as relações de subordinação e ordenação entre os conceitos), e exploram-se as relações entre proposições (palavra(s) que ligam) e conceitos.

De acordo com Guerra (1983) e Bax \& Souza (2008), mapas conceituais são diagramas - elaborados a partir de uma lista de ideias armazenadas na memória - que indicam relações entre conceitos de um conteúdo/tema/assunto de uma disciplina ou 
unidade de ensino, ou como instrumento de avaliação. Podem indicar também proposições entre dois conceitos ligados por uma unidade semântica. E, permite: organizar o conhecimento, aumentando a eficiência da aprendizagem; organizar hierarquicamente os conteúdos das diferentes disciplinas; e identificar a estrutura de um artigo, texto, conteúdo auxiliando a compreensão do aluno.

Para Amoretti \& Tarouco (2000) esses mapas são ferramentas importante no processo de aprendizagem, pois

O estudante tem um grande envolvimento pessoal na aprendizagem, constituindo por estas características, em uma pedagogia ativa, na qual os alunos podem elaborar suas conclusões sobre determinado conhecimento a partir da criação de mapas conceituais. (AMORETTI \& TAROUCO, 2000, p.04)

A figura 3 demonstra o mapeamento dos procedimentos do aluno e professor em sala de aula desenvolvido por Amoretti \&Tarouco (2000).

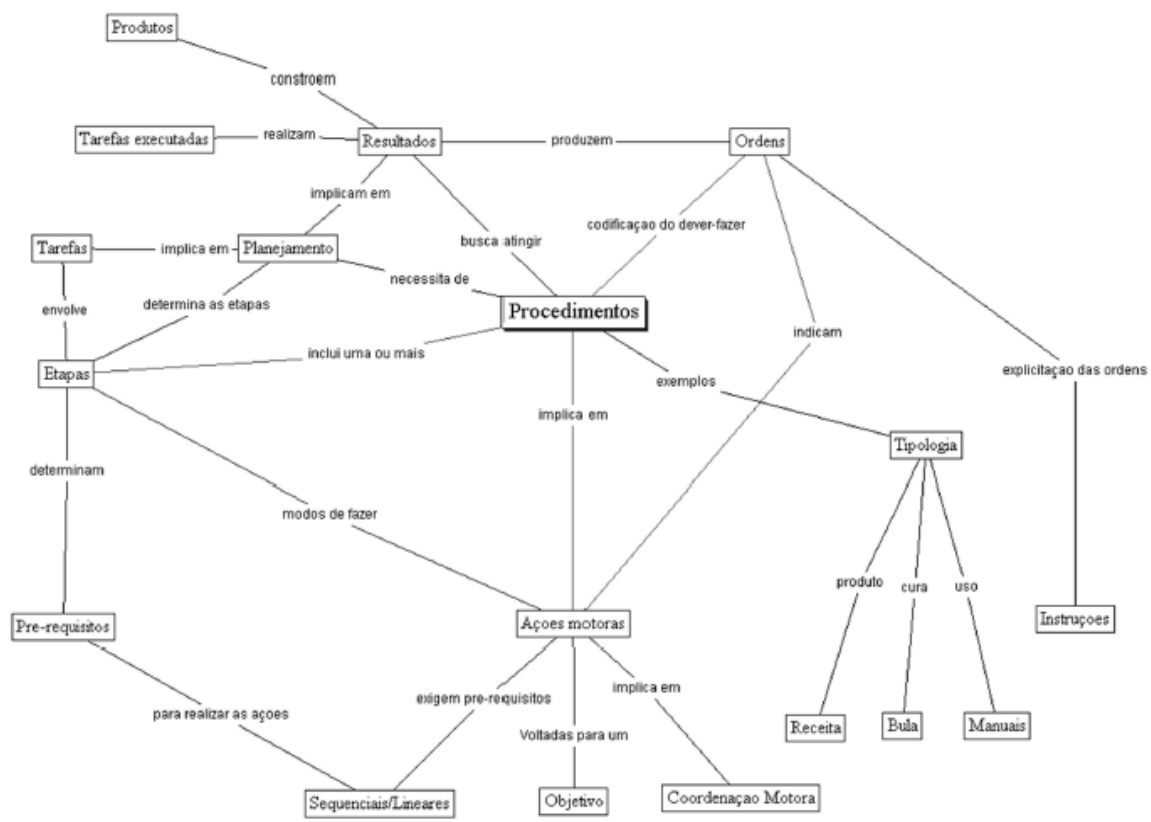

Figura 3 - Mapeamento dos procedimentos (aluno e professor).

Fonte: Amoretti \&Tarouco (2000).

Gil et al (2001) concordam que no processo de aprendizagem esses mapas são ferramentas que auxiliam nas tarefas rotineiras (vide quadro 1 ).

Quadro 1 - Mapas conceituais como apoio para aprendizagem.

\begin{tabular}{|l|l|}
\hline Apoio para aprendizagem & Como? \\
\hline Ensino de um novo tópico & $\begin{array}{l}\text { Na clarificação dos conceitos e na organização dos conceitos através de } \\
\text { ordenação sistemática. }\end{array}$ \\
\hline Reforçar a compreensão & $\begin{array}{l}\text { Reforça a compreensão e aprendizagem dos alunos e permite a } \\
\text { visualização dos conceitos chaves e resume as suas inter-relações. }\end{array}$ \\
\hline Verificar a aprendizagem & $\begin{array}{l}\text { Auxilia os professores na avaliação do processo de ensino identificando } \\
\text { os conceitos que não foram entendidos e estão faltando. }\end{array}$ \\
\hline Avaliação & $\begin{array}{l}\text { Verifica a aprendizagem do aluno analisando os mapas conceituais que } \\
\text { foram construídos. }\end{array}$ \\
\hline
\end{tabular}

Fonte: adaptado de Gil \& Silva e colaboradores (2001). 
Nesses mapas, os conceitos mais abrangentes ou gerais são colocados no topo. À medida que se desce são encontrados conceitos intermediários, que são subordinados e conectados através de uma ligação semântica. A seguir será abordado sobre as etapas do método utilizado para aplicar os mapas mentais e conceituais no ensino da representação gráfica nos cursos de design.

\section{Processo de aplicação dos mapas mentais e conceituais no ensino}

De acordo com Lakatos \& Markoni (2007), a pesquisa pode ser classificada como aplicada e exploratória, que utiliza técnica da observação, pois seu resultado será aplicado na melhoria da qualidade do ensino da representação gráfica nos cursos de Design. O processo que a caracteriza inclui as etapas: situações que possam gerar problemas adequados ao nível cognitivo dos alunos; discussão das perguntas e hipóteses dos alunos, estabelecendo direcionamento para a ação; elaboração de projetos gráficos com a participação efetiva dos alunos; coleta de informações por meio de atividades práticas, condições para a discussão coletiva, o registro das informações, com utilização de diferentes técnicas, e outros recursos (vide figura 4).

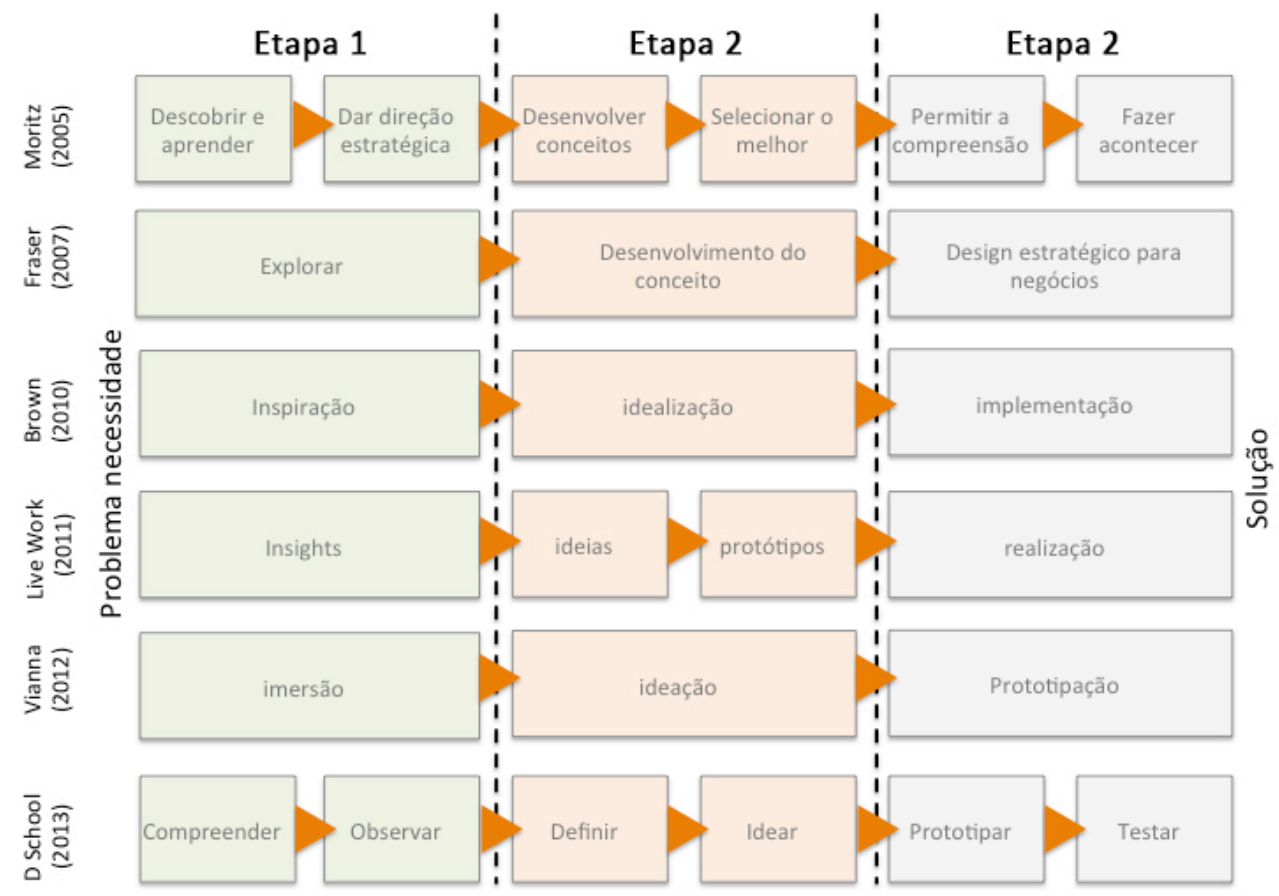

Figura 4 - Síntese de vários conceitos do processo Fonte: Elaborado pelos autores.

A etapa 1 é a parte informacional (descobrir, aprender, explorar, observar), que serve para: apresentar problemas acessíveis ao entendimento dos alunos, que gerem interesse e proporcionem uma concepção preliminar da tarefa; ligar os problemas à prática social dos alunos e ao seu cotidiano; levantar as concepções prévias dos alunos sobre os problemas; colocar os alunos em contato com o tema a ser desenvolvido (contextualização), procurando despertar sua curiosidade e motivando-os para a aprendizagem; orientar os alunos para a busca de informações.

A etapa 2 expõe a parte conceitual, que consisti na utilização de ferramentas estratégicas dos mapas, focando no contexto temático individual e coletivo. As 
atividades realizadas buscam integrar informações que darão suporte para o entendimento da representação gráfica e a sua importância nos cursos de design. É o momento em que os alunos investigam os problemas, com orientação do professor, e este deve fazer proposições sobre as técnicas de ensino e materiais didáticos a serem utilizados. Trata-se de: levantar as possibilidades de solução do problema; propor estudos de textos e realização de atividades utilizando os mapas e que auxiliem na discussão do tema; propor observações e atividades relacionadas ao tema e aos problemas com o uso dos mapas; estabelecer correlações com outras áreas; e realizar a construção do mapa mental individualmente e conceitual coletivamente.

No trabalho individual, cada aluno desenvolverá o mapa mental visando aprofundar os conteúdos da disciplina tendo como tema central "o estudo da representação gráfica nos cursos de design". Para a construção do mapa (vide figura 5) pode ser usado papel e canetas coloridas, desenhos e recortes de figuras, ou com softwares específicos. No trabalho coletivo cada grupo (com quatro alunos), deverá realizar a integração dos conceitos abordados nos mapas mentais e construir o mapa conceitual, orientado pelo professor. O mapa conceitual deverá ser apresentado em sala de aula e gerar discussão do tema central e conteúdo.

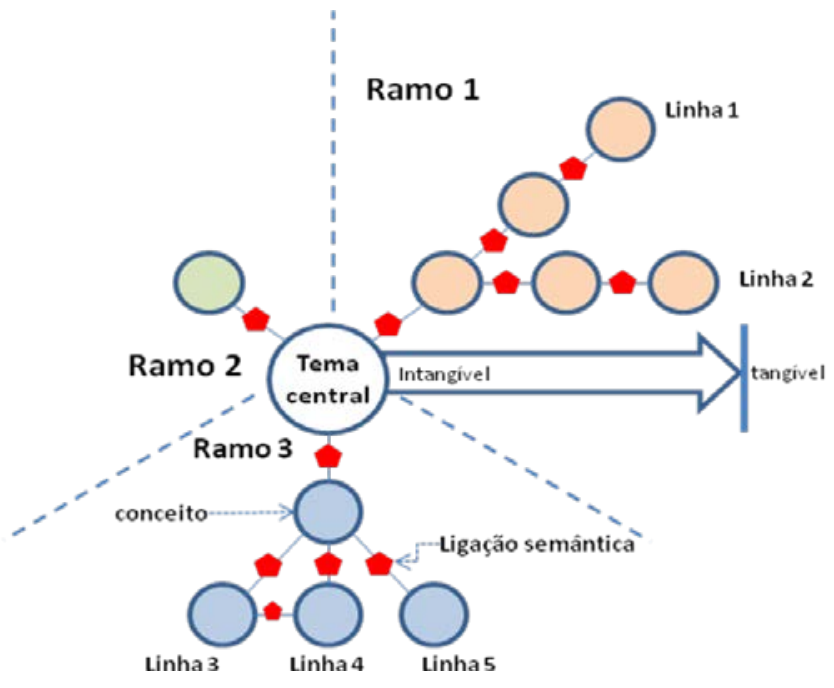

Figura 5 - Síntese de vários conceitos do processo

Fonte: Elaborado pelos autores.

A terceira etapa é a síntese e materialização, que consisti em materializar o conteúdo explorado através do desenvolvimento de um projeto gráfico, onde os alunos irão utilizar todo conhecimento adquirido. E, o professor deve coordenar as atividades que permitam: retomar as questões iniciais e discutir o que os alunos conseguiram obter de informações; solicitar sínteses e propor aplicações de conceitos; responder questões e provocar o levantamento de outros problemas; contextualizar o assunto estudado na prática social; realizar uma discussão com a classe sobre os problemas analisados; e organizar a divulgação do material produzido pelos alunos (projeto gráfico individual). Neste momento será realizado o "fechamento" do projeto, que pode ser feito através de apresentações dos resultados para a classe. 


\section{RESULTADOS}

Esse trabalho, com o uso dos mapas mentais e conceituais, originou discussão de conteúdos importantes para o estudo da representação gráfica nos cursos de design. A formulação de problemas explorados a partir de um tema é a forma mais comum de aproximar os alunos do processo de investigação, e fundamental para auxiliá-los a explorar suas hipóteses sobre determinado conhecimento. A possibilidade de um problema mobilizar a ação dos alunos, levando-os a aprendizagem, depende de vários fatores como: os conhecimentos prévios que eles têm sobre o assunto; a relação dos problemas com aspectos do seu cotidiano; a disponibilidade de informações acessíveis e compatíveis com sua capacidade cognitiva, que desperte a sua curiosidade. Porém, o processo de ensino e aprendizagem não é chegar a uma resposta correta para cada problema, mas saber lidar com as diferentes opiniões.

Conforme os resultados o uso dos mapas, determinou um canal de informação na sala de aula, facilitando a memorização e proporcionando o conhecimento do conteúdo para os alunos. Além disso, inteirou os alunos no processo de pesquisa sobre a representação gráfica desenvolvendo conceitos necessários para a construção do projeto gráfico, pois o conteúdo teórico forneceu base para o conteúdo prático. A figura 6 mostra os mapas mentais construídos individualmente.
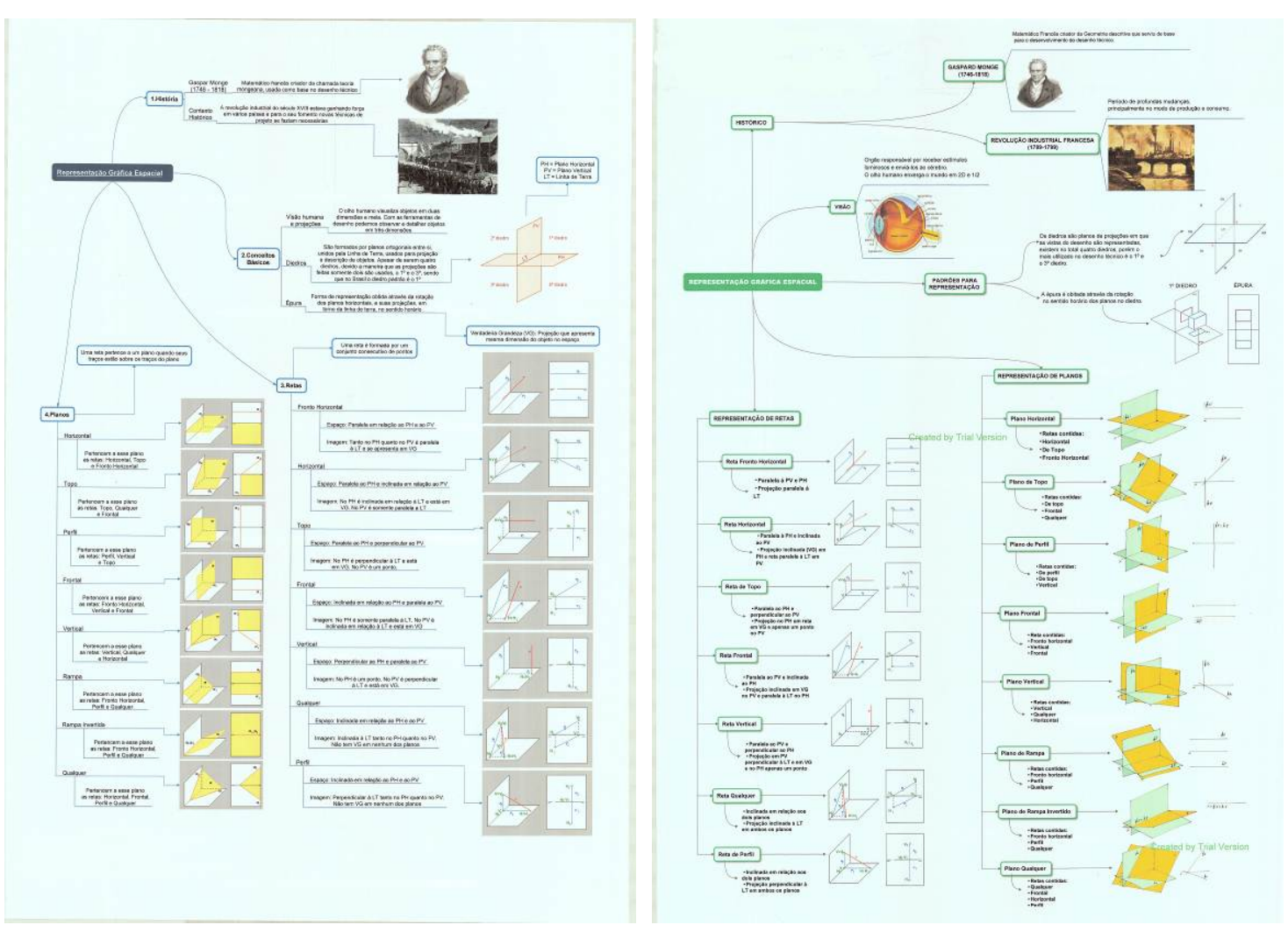

Figura 6 - Mapa mental de cada aluno do grupo 04 (continua)

Fonte: Elaborado pelos alunos. 

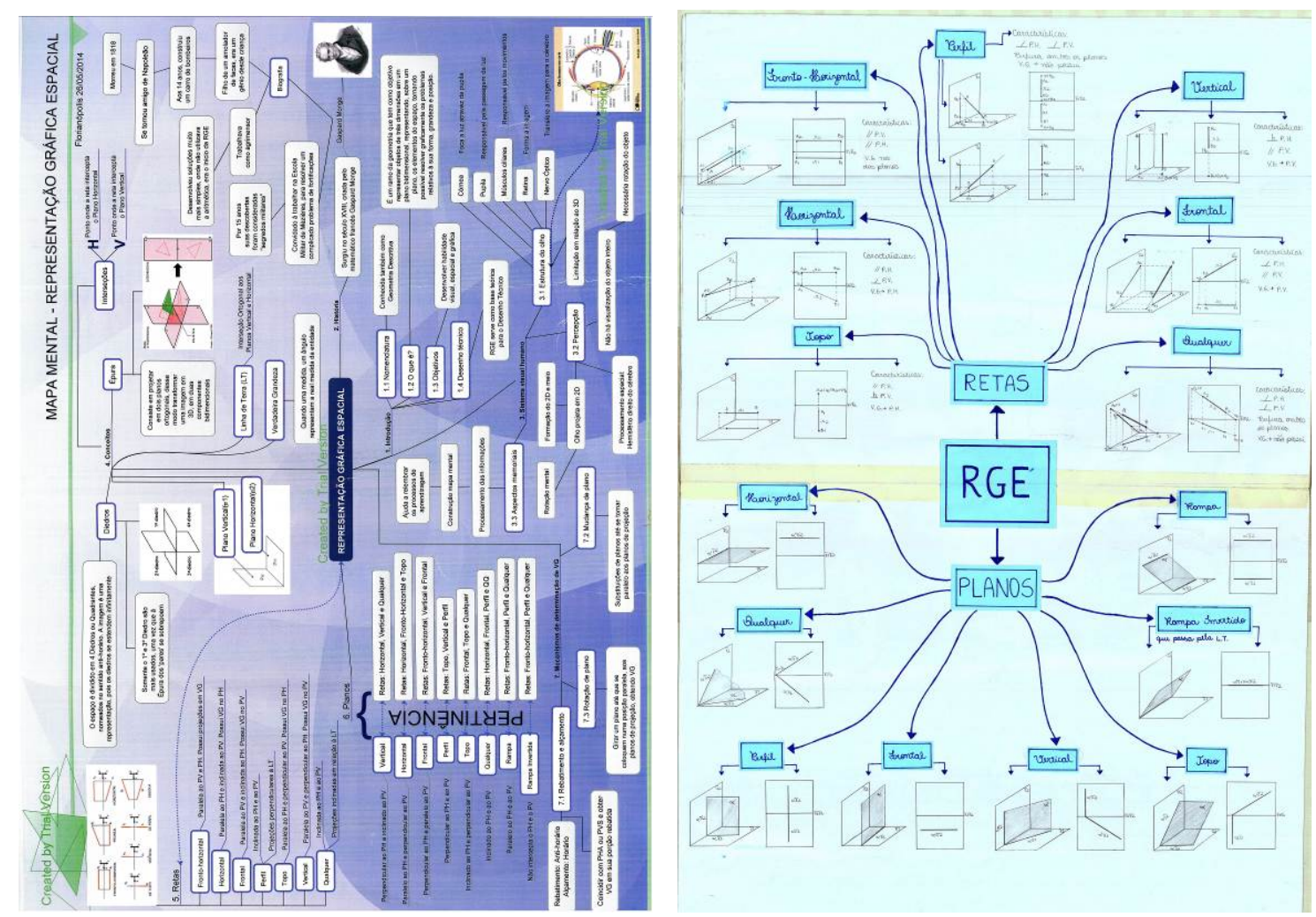

Figura 6 - Mapa mental de cada aluno do grupo 04 Fonte: Elaborado pelos alunos.

Com a integração dos mapas mentais, realizou-se a construção dos mapas conceituais em grupo (vide figura 7), no qual eles compartilharam ideias, conceitos, conhecimentos, teorias, etc, beneficiando o processo de criação dos projetos gráficos que foram realizados individualmente por eles.

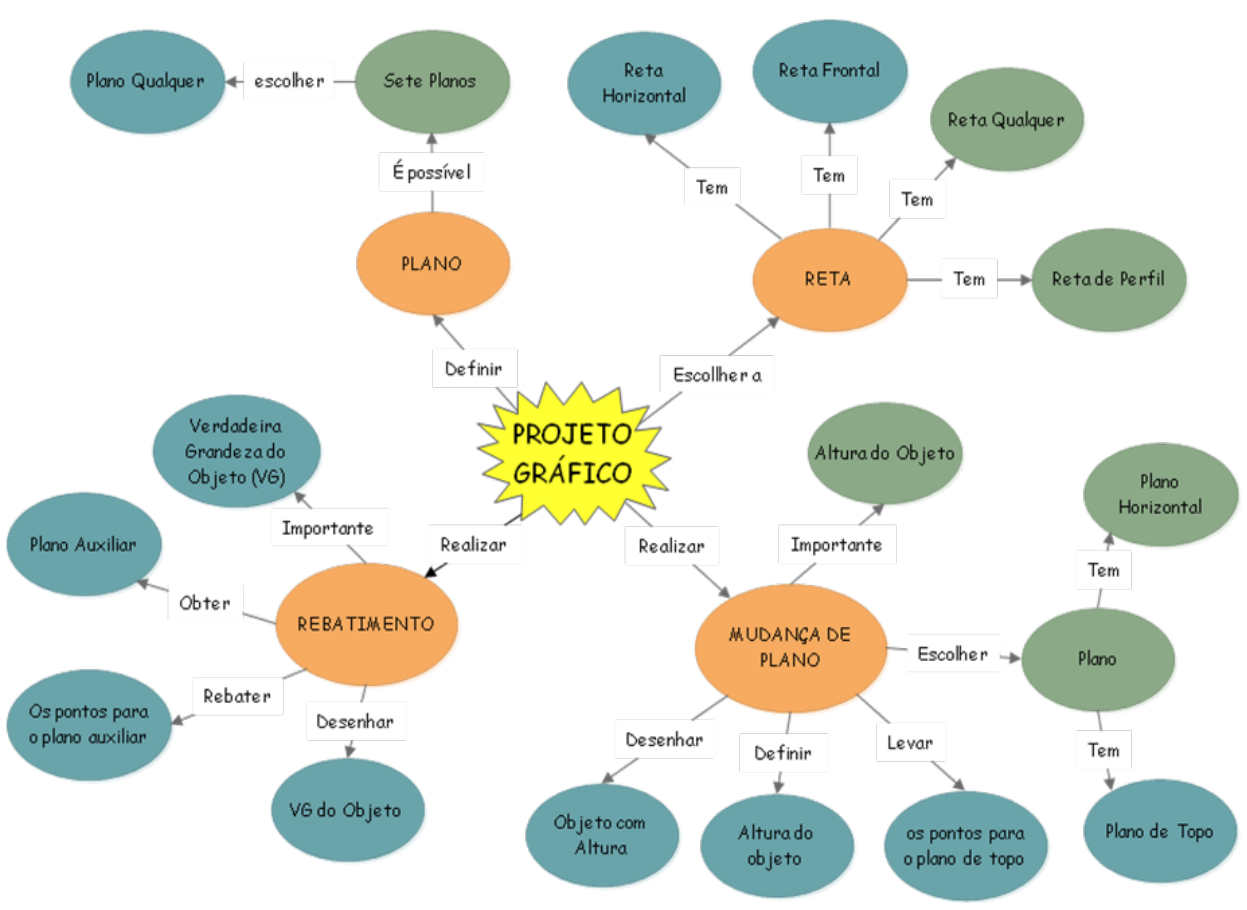

Figura 7 - Mapa conceitual do grupo 04

Fonte: Elaborado pelos alunos. 
As figuras 8 e 9 apresenta o projeto gráfico realizado pelos participantes do grupo 04 . Para o desenvolvimento desses projetos foi mostrado exemplos do que podia ser representado graficamente e os alunos ficaram livres para escolher o objeto.

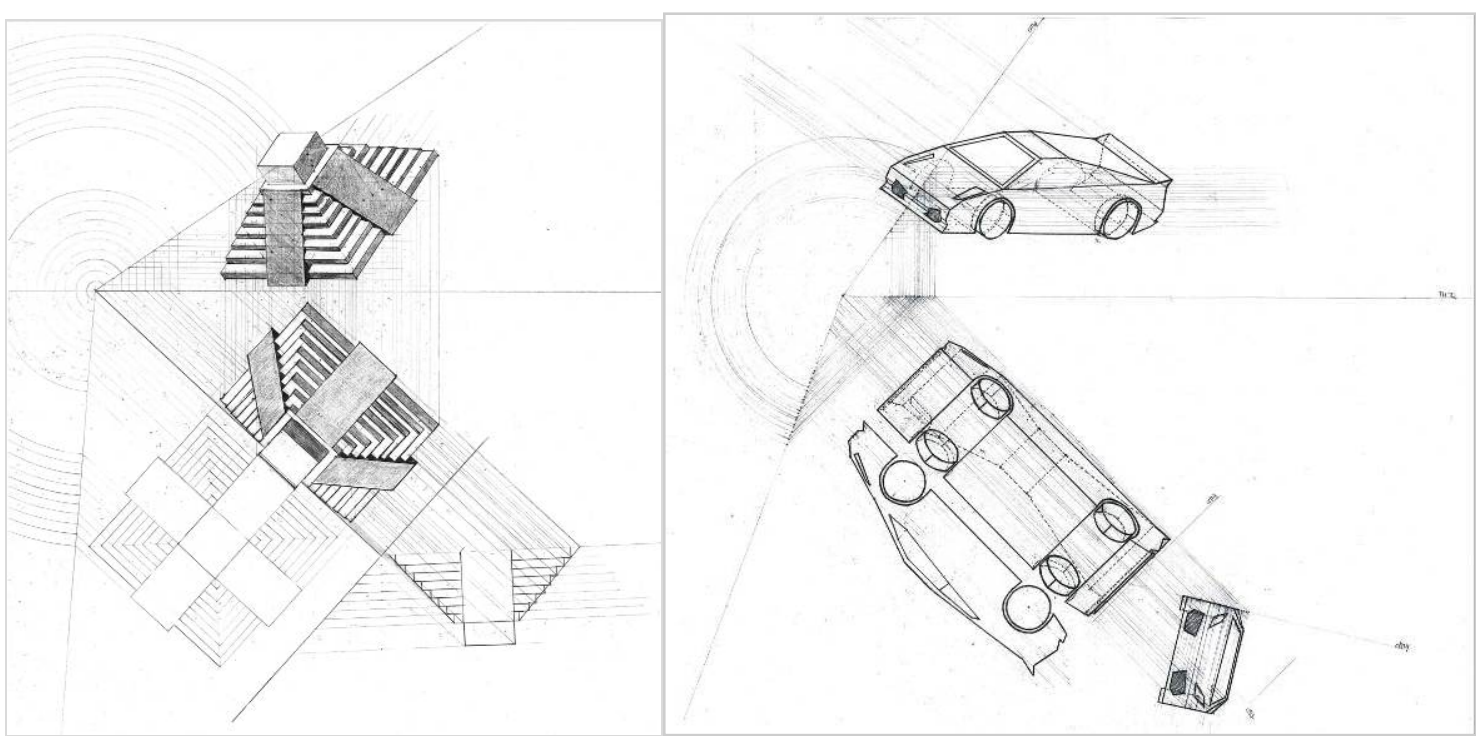

Figura 8 - Projeto gráfico de cada aluno do grupo 04 Fonte: Elaborado pelos alunos.

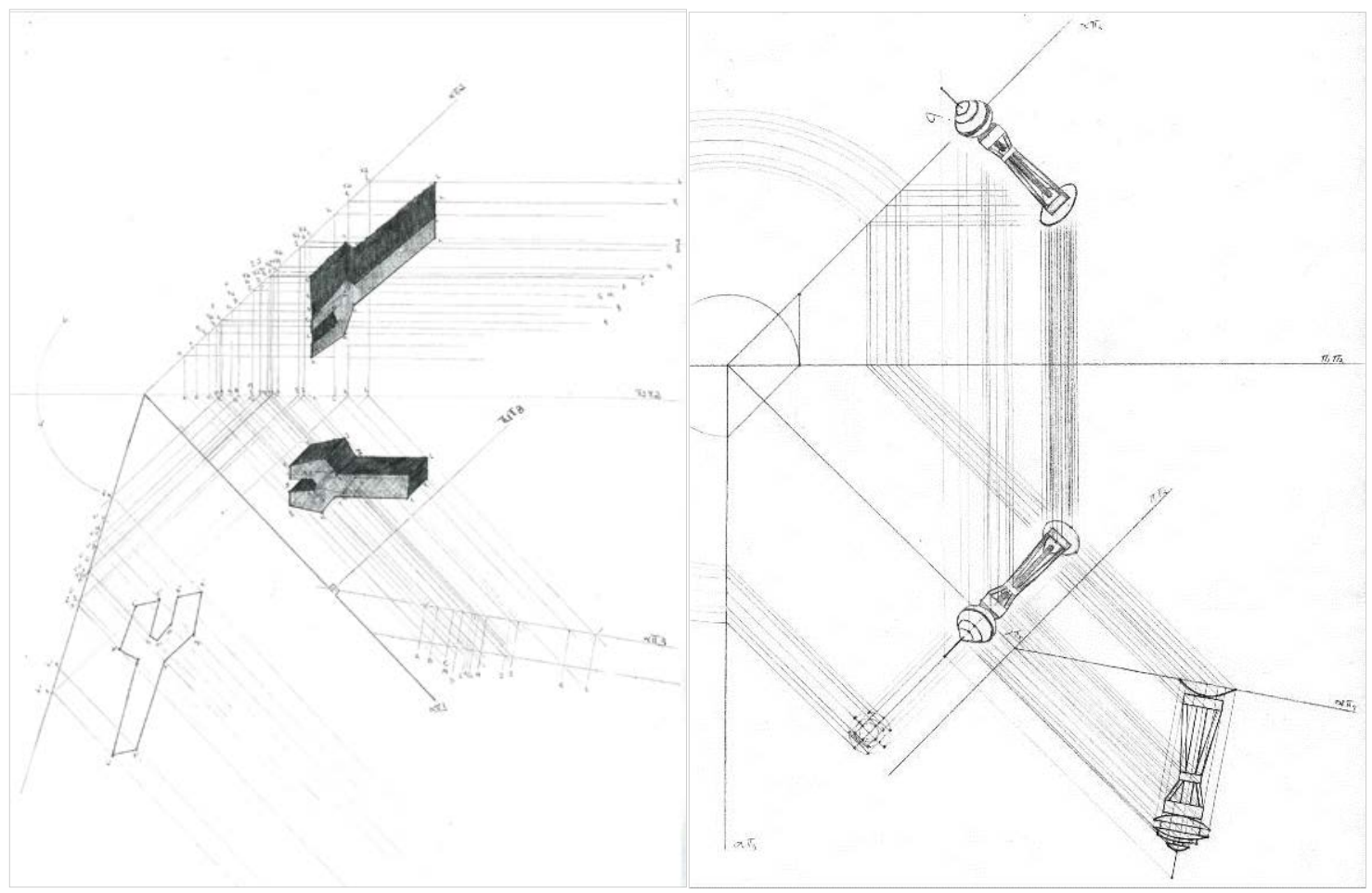

Figura 9 - Projeto gráfico de cada aluno do grupo 04 Fonte: Elaborado pelos alunos.

Com isso, é possível notar que os mapas mentais e conceituais contribuíram significativamente para a construção dos projetos gráficos, os embasando com conceitos apropriados e propiciando a aprendizagem dos alunos. 


\section{CONCLUSÃO}

O Construtivismo Piagetiano argumenta que os seres humanos são capazes de criar conhecimentos mais sofisticados, quanto melhor forem as suas interações com o mundo. Sair de um estado de menor conhecimento a um conhecimento superior depende da qualidade dessas interações, de estratégias de aprendizagem adequadas e da forma como são conduzidas (CÓ, 2007).

Neste estudo, os mapas mentais e conceituais no contexto do ensino e aprendizagem da representação gráfica para os cursos de Design demonstraram ser estratégias eficientes, pois proporcionou aos alunos: melhor compreensão do conteúdo; participação efetiva no processo; capacidade de investigar, buscar e sintetizar as informações, classificar, ordenar e estabelecer relações entre conceitos; construindo o conhecimento sobre o tema.

Esses mapas, utilizados como ferramentas estratégicas neste trabalho, mostram-se promissores no contexto da busca da informação e do conhecimento sobre a representação gráfica, somando-se ao fato de que o ensino desse conteúdo geralmente não adota ou realiza a sistematização do uso dessas ferramentas - que positivamente irá proporcionar uma melhor compreensão do conteúdo.

Ao longo de todo ensino da representação gráfica, a importância de determinados pontos devem ser analisados sob múltiplos aspectos. Nos parâmetros curriculares do curso citado, vários tópicos de conteúdos relacionados ao tema desta pesquisa favorecem esse tipo de análise e revelam algumas questões e ideias fundamentais para a aprendizagem de conteúdos conceituais, como: estimular a curiosidade; motivação; aprendizado; desenvolver o senso cognitivo dos alunos através das atividades propostas; oferecer estratégias que o professor pode ter disponível como meio para o ensino.

\section{REFERÊNCIAS}

AMORETTI, M. S. M.; TAROUCO, L. M. R. Mapas Conceituais: modelagem colaborativa do conhecimento. PGIE-UFRGS Informática na Educação: Teoria \& Prática. V. $3 \mathrm{~N}^{\circ} 1$, Setembro, 2000.

AUSUBEL, D.P. Educational Psychology: A cognitive View. New York: Holt, Rinechart and Winston, 1968.

BAX, M. P.; SOUZA, R. R. Uma Proposta de Uso de Agentes e Mapas Conceituais para Representação de Conhecimentos Altamente Contextualizados. 2008. Disponível em: <http://www.bax.com.br/research/publications/agentes>. Acesso em: 20 dez. 2015.

BUZAN, T. Saber Pensar. Editorial Presença, Lisboa, 1996.

CÓ, F. A. A aplicação de uma estratégia lúdica de ensino-aprendizagem para garantir o desenvolvimento simultâneo dos pensamentos enxuto e sustentável na construção civil. 2007. Tese (Doutorado em Engenharia Civil) - Programa de Pós-Graduação em Engenharia Civil, Universidade Federal Fluminense, Niterói - RJ, 2007.

DUARTE, G. D.; COSTA, A. C. R. Recursos Virtuais Cooperativos para Educação a Distância em Cursos de Construção Civil. Disponível em: <http://inf.unisul.br/ ines/ workcomp/cd/pdfs/2283.pdf >. Acesso em: 20 dez. 2015. 
GARGIONI DE SOUZA, L. I. O Redesign da Informação no Processamento da Imagem. 2004. Tese (Doutorado em Engenharia de Produção)- Programa de Pós-graduação em Engenharia de Produção, Universidade Federal de Santa Catarina, Florianópolis - SC, 2004.

L. I. G. de Souza. A cognição da Imagem e suas implicações no processo de ensinoaprendizagem. Florianópolis/SC, Dissertação (Mestrado em Engenharia de Produção) PPEGP/UFSC, 2000.

GIL, G. S.; SILVA, M. B. C. C. C. RIZZO, R. L. BRANDÃO, S. F. M. A modelagem da representação do conhecimento sob a forma de mapas conceituais. 2005. Disponível em: <http://websmed.portoalegre.rs.gov.br/escolas/emilio/autoria/artigos2005/ma pas_conceituais.pdf $>$. Acesso em: $20 \mathrm{dez} 2015$.

GUERRA, W. A. Mapas conceituais como instrumentos para investigar a estrutura cognitiva em Física. Dissertação de Mestrado. Porto Alegre, 1983.

HERMANN, Walther. Saber aprender - uma visão panorâmica. Disponível em: <http:// www.idph.net/artigos/idph/saberaprender.shtml>. Acesso em: 20 dez. 2015.

LAKATOS, E.M.; MARCONI, M.A. Metodologia Cientifica. São Paulo: Atlas, 1992.

Mapa Mental de Química (Hidrocarbonetos). Disponível em: <http://desconversa. com.br/quimica/mapa-mental-hidrocarbonetos/>. Acesso em: 20 dez. 2015.

MORETTO, V. P. Construtivismo: a produção do conhecimento em aula. Rio de Janeiro: DP\&A editora, 2003. 